\title{
Possíveis contribuições da psicologia para a educação sexual em contexto escolar
}

\author{
Possible contributions of psychology to sex education in school context
}

\author{
Ana Flora Müller Moura ${ }^{[a]}$, Ana Paula Pacheco ${ }^{[b]}$, Cauê Fantin Dietrich ${ }^{[c]}$, Andréa Vieira Zanella ${ }^{[\mathrm{d}]}$ \\ [a] Psicóloga, formada pela Universidade Federal de Santa Catarina (UFSC), Florianópolis, SC-Brasil, e-mail: manaflora@yahoo.com.br \\ [b] Psicóloga, formada pela Universidade Federal de Santa Catarina (UFSC), Florianópolis, SC - Brasil, e-mail: anninhahh@yahoo.com.br \\ [c] Psicólogo, formado pela Universidade Federal de Santa Catarina (UFSC), Florianópolis, SC - Brasil, e-mail: caue_17@hotmail.com \\ [d] Professora do Departamento e do Programa de Pós-Graduação em Psicologia da Universidade Federal de Santa Catarina (UFSC), \\ bolsista em produtividade do CNPq, supervisora durante o estágio, Florianópolis, SC - Brasil, e-mail: azanella@cfh.ufsc.br
}

\section{Resumo}

O presente trabalho teve como objetivo a reflexão, a partir de uma experiência de estágio curricular, das possíveis contribuições da psicologia para a efetivação das propostas apontadas nos Parâmetros Curriculares Nacionais, os PCN, referentes ao trabalho de orientação sexual no contexto escolar. Sendo assim, realizou-se um trabalho de intervenção psicológica em uma escola estadual de Santa Catarina com estagiários em psicologia escolar do curso de graduação da Universidade Federal de Santa Catarina. O trabalho teve como base as contribuições de Vygotsky e outros autores correlatos que desenvolveram estudos a respeito das relações entre desenvolvimento e aprendizagem. Nesse contexto escolar específico foi feita uma análise do modo como a temática sexualidade vinha sendo abordada nas turmas de ensino fundamental dessa escola. Percebeu-se o despreparo dos profissionais em educação para lidar com o tema, bem como a necessidade de uma formação complementar adequada para o desenvolvimento deste trabalho.

Palavras-chave: Sexualidade. Educação sexual. Parâmetros Curriculares Nacionais. Psicologia escolar. Perspectiva histórico-cultural.

\section{Abstract}

The objective of this paper is to reflect about the possible contribution of psychological intervention to validate the proposals made by the National Curriculum Parameters regarding to the sexual orientation work in school environment from a curricular trainee experience in psychology in a public school. The trainee experience set parameters for the arguments here presented, which are fundamented on the 
contributions of Lev S. Vygotsky as well as other authors who developed studies about the relations between development and learning. In the school context where the intervention took place, an analysis of how sexuality was being approached in elementary school was made. It was evident that the professionals were unprepared to handle the topic, as well as the need of complementary instruction in order to develop a work that considers the complexity of the matter.

Keywords: Sexuality. Sexual education. National Curriculum Parameters. School psychology. Historic-cultural perspective.

\section{Introduçáo}

Os Parâmetros Curriculares Nacionais ${ }^{1}$ consistem no referencial nacional a partir do qual o sistema de ensino fundamental e médio está organizado. Eles compreendem um conjunto de cadernos elaborados e fornecidos pelo governo federal às escolas de todo o território nacional, cadernos esses que apresentam os pressupostos norteadores a serem efetivados em projetos educativos nas salas de aula.

O papel da escola está repensado nos PCN. Diferentemente da perspectiva de que concebia o professor como transmissor de conhecimentos ao aluno, a concepção de ensino/aprendizagem vigente nos PCN considera-o como um processo que envolve, além do conhecimento do próprio professor, os conhecimentos e saberes dos alunos. O professor atua, nessa perspectiva, como um mediador desse processo. A mediação, por sua vez, deve envolver ainda os pais, o governo e a sociedade, no processo de ensinar e aprender.

Para os PCN a organização dos projetos educativos do ensino fundamental e médio deve abranger obrigatoriamente conhecimentos de língua portuguesa, matemática, história, geografia, ciências naturais, educação física, arte elíngua estrangeira, bem como a abordagem transversal de temas sociais, sem restringi-los à abordagem de uma única área, isto é, sem transformá-los propriamente em uma disciplina.

[...] Os temas transversais constituem-se nas problemáticas sociais em relação à ética, saúde, meio ambiente, pluralidade cultural, orientação sexual e trabalho e consumo [...] não se constituem em novas áreas mas num conjunto de temas que aparecem transversalizados permeando a concepção das diferentes áreas, seus objetivos, conteúdos e orientações didáticas (PCN, 1997, p. 65).

Esses temas envolvem problemáticas sociais atuais e urgentes, em nível nacional e mundial, exigindo adaptações relacionadas à região ou à própria escola. Para fins deste estudo, nos deteremos à reflexão de apenas um destes temas transversais, a saber, a orientação sexual.

Os PCN (1998, p. 67) propõem que a escola trate a sexualidade como "algo fundamental na vida das pessoas, questão ampla e polêmica, marcada pela história, pela cultura e pela evolução social". O trabalho com foco na sexualidade deve, segundo essas diretrizes, considerar as emoções e noções sobre sexualidade trazidas pelos alunos, oriundas da família e de suas vivências, e possibilitar reflexões e debates que assegurem a construção da autonomia dos sujeitos, a capacidade de discernimento e escolha quanto ao exercício de sua própria sexualidade. Os PCN orientam que a escola não deve concorrer com o saber aprendido na família, nem concorrer com os seus valores, mas complementá-los.

A escola, ainda segundo os PCN, lugar de convívio de crianças, jovens e adultos, constitui-se em um lugar privilegiado de manifestações da sexualidade nas diversas etapas da vida dos sujeitos. Com essa condição deve possibilitar informações atualizadas do ponto de vista científico e dos valores morais atribuídos a determinados comportamentos, discutir tabus, preconceitos, discutir as mensagens dos meios de comunicação, da própria família e da sociedade, assegurando ao aluno condições para que ele desenvolva atitudes coerentes com os seus valores. Temas como doenças sexualmente transmissíveis,

\footnotetext{
1 Informações sobre os Parâmetros Curriculares Nacionais são encontradas no endereço eletrônico do Ministério da Educação. Recuperado em: 20 dez. 2010 e disponível em: <www.mec.gov.br>.
} 
virgindade, homossexualidade, preconceito, questões de gênero e, sobretudo, gravidez indesejada na adolescência e HIV são preconizados pelos PCN.

Para melhor conhecermos o que tem sido discutido e de que forma se tem trabalhado com a temática orientação sexual nos contextos escolares, recorremos à pesquisa em algumas bases de dados. As pesquisas foram feitas no período de 24/09/2008 a 04/12/2009 nas bases virtuais SciELO, Periódicos. Capes, Indexpsi, Ibict, Bvs-psi, com os seguintes descritores: orientação sexual, educação sexual, sexualidade e sexualidade e educação. No total, foram encontrados 555 artigos nos idiomas português, inglês e espanhol, com maior incidência nas áreas de psicologia, enfermagem e pedagogia. Destes, consideramos as publicações em português, relacionadas à psicologia e à educação, totalizando 56 trabalhos, dentre os quais questões de gênero, relatos de experiência, prevenção de doenças e promoção de saúde, gravidez na adolescência, capacitação dos educadores e reflexões sobre os PCN são as temáticas principais.

De modo geral, nesses trabalhos discute-se o aspecto constitutivo da sexualidade no ser humano, sexualidade iniciada na infância e desenvolvida nas diferentes fases do desenvolvimento, e que éinerente, portanto, tanto ao aluno quanto ao professor e aos demais funcionários da escola. Discute-se ainda: as (im)possibilidades do trabalho de orientação sexual segundo os PCN, uma vez que na prática esse trabalho tem ficado relegado às aulas de ciências; a necessidade de capacitação dos profissionais para essa lida; e a biologização da sexualidade, que pressupõe o aspecto puramente genital da sexualidade e exclui nas intervenções e reflexões, a dimensão emocional.

Alguns autores como Altmann (2001, 2007), Bretãs e Silva (2005) chamam a atenção para os objetivos da educação sexual na escola e, de certa forma, problematizam o que é preconizado nos PCN, apontando que a escola não seria absolutamente neutra em seus interesses. Além de seu papel fornecedor e provocador de conhecimento, também atuaria como um meio de controle e coerção social, buscando produzir sujeitos autodisciplinados no que se refere à maneira de viver a sua sexualidade (Altmann, 2001).
Altmann (2007, p. 3) aponta a sexualidade como:

importante foco de investimento político e instrumento de tecnologia de governo", e considera o espaço escolar como privilegiado para o controle e exercício do poder, do biopoder ${ }^{2}$, através de práticas de gerenciamento da vida sexual das crianças e dos jovens e da regulação das populações. Isso porque a escola possibilita a relação entre a comunidade, a informação e a transmissão de conhecimento, por meio da educação sexual: quando a escola é chamada a intervir ela busca intervir na vida do corpo e na vida da espécie, na saúde individual e coletiva, na vida dos jovens bem como na regulação e organização da população.

Outro aspecto relevante relacionado à educação sexual refere-se à transmissão da moralidade.

O termo responsabilidade é muito utilizado como um instrumento repressivo [...] impõe a culpa [...] impedindo que os jovens possam assumir a verdadeira responsabilidade de estarem juntos em uma inter-relação segura do ponto de vista da saúde sexual, com troca recíproca de amor e prazer (Brêtas \& Silva, 2005, p. 329).

A questão da gravidez, por exemplo, pode ser pensada como o resultado de um processo social e cultural e não apenas como um dado biológico, que não considera a afetividade, o sentimento, a escolha. Gravidez na adolescência não significa, nesse sentido, necessariamente um problema.

Esses autores apontam para o "perigo" do trabalho de orientação sexual baseado apenas na perspectiva higienista, próximo ao discurso médico, restrito a conhecimentos anatômicos dos corpos e aos livros didáticos de ciências, desconsiderando o desenvolvimento psíquico dos sujeitos que é engendrado nas relações sociais.

Meirelles (1997) argumenta, ainda, que sexualidade, família e escola (ou qualquer instituição que se dedique à educação), devem ser pensadas a partir do princípio da não exclusão, ou seja, sistemas

2 O biopoder, modelo de controle social, denominado por Michel Foucault no século XX, é marcado pelo investimento político na vida e na sua sexualidade dos sujeitos. 
que devem interagir entre si por meio de vinculação, união e respeito pelas diferenças.

Cientes dessas críticas e reconhecendo a importância do trabalho de educação sexual, desenvolveu-se uma intervenção psicológica com alunos de $5^{a}$ a $8^{a}$ séries $^{3}$ do ensino fundamental de uma escola pública de Florianópolis, SC. O diálogo entre os pressupostos preconizados nos $\mathrm{PCN}$, a literatura encontrada e a intervenção realizada consistem no foco deste artigo, que objetiva, com esse diálogo, contribuir com as reflexões sobre as possíveis contribuições da psicologia para o trabalho de orientação sexual em contexto escolar.

\section{Breves consideraçóes teóricas}

A sexualidade, após as contribuições de Sigmund Freud, deixa de ser entendida como exclusiva do mundo adulto e ganha, a partir de então, outro olhar. Um olhar que compartilharemos aqui, em que a sexualidade é reconhecida como constituinte da vida do sujeito, estando sempre relacionada a outras dimensões de sua existência, como gênero, trabalho, lazer, formação, religião.

No processo de formação escolar dos alunos a sexualidade ocupa, como visto anteriormente, um lugar de tema transversal, assim como os temas ética, etnia, pluralidade cultural, saúde e meio ambiente. Com essa condição, a sexualidade não é transformada em uma disciplina, já que supostamente não deveria ser tema exclusivo de uma aula, mas pervagante e transversal a todas. Adotamos neste artigo, confluindo com os PCN, uma visão que compreende os seus aspectos biológicos, psicológicos e sociais da sexualidade, podendo então ser abordada e encarada por diversos vieses e em variados contextos, o que significa considerar a intervenção relacionada a esse tema como em constante processo de reinvenção. Por sua vez, o alerta feito por Altmann (2007) sobre os riscos de se fazer da orientação sexual um exercício para o controle da vida, foi também considerado.

A importância que a sexualidade tem como tema transversal se deve, entre outros fatores, a uma tensão política que se estabelece entre o governo e as juventudes. A gravidez na adolescência, nas últimas décadas, passou a ser percebida como um problema, uma vez que interfere fortemente em índices demográficas/populacionais. E a epidemia da aids, disseminada como tantas outras doenças sexualmente transmissíveis (DSTs), também preocupa cada vez mais os responsáveis pela saúde em razão das altas estatísticas e custos, exigindo, entre várias medidas, uma forte conscientização da população em relação aos cuidados preventivos.

Em decorrência, o tema da sexualidade conquistou seu espaço na escolarização formal. A forma de tratamento desse tema na escola, consequentemente, mudou, visto que mesmo não sendo este antes, oficialmente, um tema transversal, certamente apareciam questões relacionadas à sexualidade em todos os espaços escolares, ainda que a reflexão sobre eles não necessariamente acontecesse.

Conforme Foucault (1988), desde o século XVIII a instituição pedagógica codificou conteúdos e qualificou locutores para falarem do tema sexualidade.

Falar do sexo das crianças, fazer com que falem dele os educadores, os médicos, os administradores e os pais [...] o sexo das crianças e dos adolescentes passou a ser um importante foco em torno do qual se dispuseram inúmeros dispositivos institucionais e estratégias discursivas (Foucault, 1988, p. 32).

Segundo a perspectiva foucaultiana, a educação sexual na escola seria apenas mais um mecanismo de disciplinarização dos corpos, onde o educador, representando a instituição escola, que por sua vez representa a instituição governo e este a sociedade, reproduz para o aluno as repressões sexuais historicamente produzidas e socialmente partilhadas.

Reconhecendo, porém, a importância da educação sexual para a sociedade, permanece a dúvida: de que modo ela acontece e quais seus efeitos para a escola e principalmente para os alunos? Sendo os PCN incorporados e postos em prática em relação a esse tema, consideramos que a educação sexual em contexto escolar pode ter um papel diferente da

\footnotetext{
3 A escola está em processo de adaptação à nova lei (n. 11.274/02/06) que regulamenta o ensino fundamental de 9 anos. Ainda mantém turmas até a $8^{\mathrm{a}}$ série e, no momento, há 6 turmas com no máximo 20 alunos por sala; destas, duas são de $5^{\mathrm{a}}$ série e duas são de $6^{\mathrm{a}}$ série (Brasil, 2006).
} 
lógica disciplinarizadora que a vem caracterizando: acreditamos ser possível criar, em contextos escolares, espaços onde o tema seja apresentado, discutido e significado de outras formas. Esse pressuposto foi por nós assumido como norte para as intervenções nas oficinas de sexualidade que promovemos na escola.

Os próprios PCN trazem da Organização Mundial da Saúde, de 1975, uma diretriz que coaduna com essa aposta:

a sexualidade forma parte integral da personalidade de cada um. É uma necessidade básica e um aspecto do ser humano que não pode ser separado de outros aspectos da vida. A sexualidade não é sinônimo de coito e não se limita à presença ou não do orgasmo. Sexualidade é muito mais do que isso, é energia que motiva encontrar o amor, contato e intimidade, e se expressa na forma de sentir, na forma das pessoas tocarem e serem tocadas. A sexualidade influencia pensamentos, sentimentos, ações e interações e tanto a saúde física como a mental. Se a saúde é um direito humano fundamental, a saúde sexual também deveria ser considerada como um direito humano básico (PCN, 1997, p. 295).

De acordo com o exposto, a educação sexual surge no meio escolar intimamente ligada a uma questão de saúde, porém é importante considerar do que se fala quando se afirma que a saúde sexual é um direito básico. Conforme a OMS (1960), saúde é compreendida não como dicotômica à doença, mas sinônimo de "bem-estar físico, psíquico e social". Saúde, portanto, é direito de todos, pois o que se espera de uma sociedade democrática é a possibilidade de uma vida digna para todos.

\section{A Sexualidade como tema da psicologia}

A psicologia tem tradicionalmente uma relação próxima com o tema da sexualidade, principalmente com o surgimento da psicanálise, que, apesar de não se considerar uma abordagem psicológica, está presente nos currículos de qualquer curso de graduação em Psicologia no País. No curso de Psicologia da UFSC, o currículo não tem nenhuma disciplina que trate exclusivamente desse tema, tornando-se ironicamente um tema transversal na formação do psicólogo.

Como destacado pela OMS, a sexualidade tem relações diretas com personalidade, pensamentos, sentimentos e especialmente com a saúde, reforçando ainda mais a ligação desta com a psicologia. Sendo assim, pelo menos nessa universidade esse tema tão fundamental em qualquer campo de atuação psi merece mais destaque e estudo.

De toda forma, o profissional psi ainda tem algum diferencial em sua formação no que diz respeito à capacitação para intervir em assuntos de sexualidade. Uma das instrumentalizações mais importantes desse profissional é a sua escuta qualificada, em que não se deve sobrepor os juízos morais, sendo essa considerada a abertura a assuntos polêmicos e à diversidade de opiniões, inclusive preconizada pelo código de ética dessa profissão, estando passível de punição quem desconsiderá-la ${ }^{4}$.

Essas qualificações, que podem ser consideradas específicas mas não exclusivas da psicologia, são de extrema importância no trabalho com a sexualidade no contexto escolar, principalmente quando essa funçãoé entendida para além de uma transmissão de informações sobre o assunto: chama-se a atenção para a dimensão afetiva inexoravelmente amalgamada ao tema e na sua forma de abordagem.

Quando acontece de não se ter nenhum profissional específico na escola responsável pela educação sexual, e isso pode ser observado na maioria das instituições escolares, inclusive onde o grupo desenvolveu o estágio, não raro os professores das disciplinas de ciências é que abordam o tema quando trabalham o corpo humano com os alunos, ainda que o tema sexualidade envolva aspectos para além do biológico, como o aspecto afetivo, sobre o qual a capacitação dos professores pode não dar conta de problematizar. O perigo envolvendo tal situação está em que:

\footnotetext{
4 De acordo com o artigo segundo do Código de Ética do Profissional Psicólogo (2005), a esse profissional é vedado: “a) Praticar ou ser conivente com quaisquer atos que caracterizem negligência, discriminação, exploração, violência, crueldade ou opressão; b) Induzir a convicções políticas, filosóficas, morais, ideológicas, religiosas, de orientação sexual ou a qualquer tipo de preconceito, quando do exercício de suas funções profissionais".
} 
esta equivalência imposta entre sexualidade e reprodução, como um fenômeno essencialmente biológico, objetivo, palpável através dos filhos gerados, ocasiona uma cisão entre a sexualidade e a subjetividade, restando apenas informações sobre reprodução, anatomia, fisiologia, AIDS e contracepção, assim deixando de lado a subjetividade, seja da criança ou do adolescente (Brêtas \& Silva, 2005, p. 328).

Sendo então a sexualidade um tema transversal que não conta com um profissional responsável, e ao mesmo tempo a queixa frequente dos professores de que o tema é um forte interveniente na sala de aula, a questão se torna, muitas vezes, uma "batata quente". Vai passando de mão em mão, e o que era responsabilidade de todos acaba sendo de ninguém.

Enxergou-se, portanto, uma relação promissora entre a psicologia e a educação sexual na escola. O psicólogo escolar hoje é um profissional que incessantemente reinventa sua prática dentre as inúmeras possibilidades de ação no contexto escolar. De acordo com Zanella (1998), esse movimento pode trazer importantes contribuições às relações sociais que se estabelecem na escola, entre os alunos, professores, gestores, pais e responsáveis, e principalmente deles entre si, sendo a sexualidade uma temática com a qual pode contribuir.

\section{Método}

A intervenção psicológica na escola lócus deste trabalho foi desenvolvida entre agosto de 2007 e dezembro de 2008. No primeiro semestre de 2008, a partir de pesquisa realizada com professores e equipe técnica da escola ${ }^{5}$, foram levantadas várias queixas a respeito das relações entre alunos, professores, equipe técnica e famílias. Durante as reuniões pedagógicas e nos conselhos de classe, por sua vez, constatou-se uma insatisfação geral dos professores com as turmas de $5^{\mathrm{a}}$ e $6^{\mathrm{a}}$ séries. Entre os principais problemas apontados pelos professores, muitos docentes destacaram a indisciplina e o desinteresse dos alunos pelos estudos, ao mesmo tempo em que apareceram queixas relacionadas com a "feminilidade" de alguns garotos e namoros durante as aulas.

A demanda por um trabalho voltado à reflexão sobre a sexualidade dos adolescentes partiu, portanto, dos professores, que ao mesmo tempo em que apontavam a necessidade de se trabalhar essa questão demonstravam dificuldades em assumir essa tarefa. Em decorrência, em reunião realizada com os professores e equipe técnica da escola acerca das problemáticas levantadas pelos professores, decidiu-se trabalhar diretamente com os alunos.

Delimitou-se como objetivo daintervenção trabalhar a temática sexualidade com os alunos de $5^{\mathrm{a}}$ a $8^{\mathrm{a}}$ séries da escola. A decisão de trabalhar com essas turmas foi discutida, pois percebeu-se que a queixa dos professores a respeito da sexualidade dos alunos estava atrelada ao comportamento dos alunos de $5^{a}$ e $6^{a}$ séries, e importante se fazia desatar esse vínculo. Por outro lado, nas turmas de $7^{\mathrm{a}}$ e $8^{\mathrm{a}}$ séries dúvidas e inquietações relacionadas à sexualidade também eram observadas. Maheirie (2005, p. 538) afirma que "a sexualidade é um fenômeno da existência humana, portanto, faz parte também da vida dos(as) adolescentes". Sendo assim, optou-se por trabalhar com as turmas de $5^{\mathrm{a}}$ a $8^{\mathrm{a}}$ séries.

A intervenção teve como norte as reflexões sobre processos de ensinar e aprender bem como sobre as relações entre desenvolvimento e aprendizagem características do enfoque histórico-cultural em psicologia. Segundo Zanella (2001), a aprendizagem em contexto escolar não se restringe à apropriação de conteúdos científicos e sim na apropriação da cultura. A intervenção objetivou promover a promoção de espaços de reflexão, debate, de encontro e confronto de variados sentidos sobre a sexualidade e seus muitos temas.

Zanella (2003,p. 157) afirma que, no espaço da sala de aula, deveriam ser constituídas zonas de desenvolvimento proximal, sendo esse conceito entendido como:

campo interpsicológico em que se apresentam temáticas que interessam aos sujeitos ali

\footnotetext{
5 A escola lócus deste trabalho tinha 250 alunos e, conforme a política do Estado, possuía na equipe de orientação pedagógica somente um técnico que realizava a função de coordenador pedagógico. Além do técnico, a escola contava com o diretor e uma secretária, porém estes não estavam presentes na referida reunião.
} 
envolvidos, que os desafiem, que vão além daquilo que eles já sabem, que possam se problematizadas, polemizadas, que possibilitem, portanto a esses sujeitos dar um salto qualitativo em relação à sua própria história, em relação ao seu próprio conhecimento, às suas experiências e ao que já sabem.

Desse modo, durante a prática de estágio procura-se realizar um trabalho de mediação entre as experiências dos alunos no que diz respeito à sexualidade, o conhecimento científico e também a diversidade de olhares sobre o tema, característicos da diversidade histórico-cultural que conota a humanidade.

O trabalho desenvolvido por Dinis e Asimelli-Luz (2007, p. 82) coadunou com as diretrizes por nós adotadas. Para os autores,

um trabalho de educação sexual significa problematizar a sexualidade, não no sentido de encará-la como problema a ser resolvido, mas de questionar as evidências, apresentar um leque de conhecimentos para que a sexualidade seja compreendida com um aspecto predominantemente histórico-cultural, e para que os discursos normativos que regem as construções de nossas imagens do masculino e do feminino, bem como as diversas imagens de ter prazer com o próprio corpo e/ou com o corpo do/a outro/a sejam desconstruídos, permitindo novas vivências acerca da sexualidade.

Após várias observações em sala de aula e nos variados espaços escolares para conhecer o modo como a sexualidade era falada ou silenciada, realizaram-se encontros com os alunos para tratar do tema. Foram realizados, em média, quatro encontros de aproximadamente uma hora e meia em cada sala, com periodicidade quinzenal, com cada uma das oito turmas de $5^{\mathrm{a}}$ a $8^{\mathrm{a}}$ séries da escola. No primeiro encontro o grupo estava presente nas diferentes turmas, com o intuito de tornar-se conhecido pelos alunos. Nos encontros posteriores, o grupo dividiu-se por turmas. Nas $5^{\text {a }}$ e $6^{\text {a }}$ séries trabalhou-se em duplas, uma vez que as turmas eram maiores - em torno de 20 alunos - e se mostraram com muita energia. Nas demais turmas, graças ao número reduzido de alunos - em torno de 10 a 15 alunos - trabalhou-se individualmente.
Algumas dificuldades emergiram ao longo do processo, em especial, com relação ao tempo de duração dos encontros e a disponibilidade da escola em abrir espaço para a intervenção em sala de aula. Em alguns encontros contou-se apenas com 45 minutos, visto que os professores não foram avisados com antecedência pela direção e ou equipe técnica. Em outros momentos, a equipe técnica solicitava nossa presença no lugar dos professores faltantes. Isso demandou uma constante adaptação do material previamente elaborado, a ser utilizado nas diferentes turmas.

A respeito das atividades realizadas com as turmas, buscou-se inicialmente compreender quais eram as dúvidas e inquietações dos alunos quanto à temática sexualidade. Nesse sentido, no primeiro momento solicitou-se que os alunos elaborassem perguntas a respeito de temas tais como: amor, paixão, casamento, afeto, saúde, violência e sexo.

A partir disso, em cada encontro com as turmas eram trabalhados temas relacionados às perguntas que os alunos trouxeram no primeiro dia de intervenção. As temáticas trabalhadas foram: família, relacionamentos amorosos e informações sobre o corpo. Para a realização das atividades, foram utilizadas como ferramentas para a intervenção: gincana, música, poesia, encenação, confecção de cartazes e apreciação de imagens tanto científicas quanto estéticas sobre sexualidade.

\section{Resultados e discussáo}

Com as oficinas, os resultados foram múltiplos e diferenciados, de acordo com cada turma e, na verdade, com cada aluno que participou. Contudo, consideramos importante apontar, neste tópico, alguns momentos das intervenções que possibilitam ao leitor compreender tanto a dinâmica dos encontros quanto o que deles emergiu.

\section{Quais perguntas os jovens fazem em relaçáo à sexualidade?}

Verificou-se que nas $5^{a}$ e $6^{a}$ séries as maiores inquietações estão relacionadas às relações afetivas de maneira geral, entre os pares, amigos e a família. Em contrapartida, nas $7^{\mathrm{a}}$ e $8^{\mathrm{a}}$ séries as principais dúvidas eram a respeito do ato sexual e das consequências 
deste. Pode-se atribuir essa diferença à idade dos adolescentes e suas experiências, visto que nesse período do desenvolvimento humano, em pouco tempo, o corpo passa por mudanças significativas que alteram a maneira de pensar e de agir das pessoas, modificando-se, assim, as relações socialmente construídas. Podemos considerar ainda que a temática do corpo humano na disciplina de ciências é ministrada nas 7 소 séries, o que pode ter contribuído nessa diferenciação

\section{A sexualidade tal como os jovens a veem}

Observou-se, tanto nas perguntas elaboradas pelos jovens como nos encontros subsequentes com as turmas, dúvidas relacionadas à masturbação, que refletem valores vigentes na cultura e na sociedade ocidental e que acarretam sentimentos de culpa, vergonha e medo com relação ao conhecimento do corpo e à experienciação da sexualidade. Alguns meninos afirmavam, por exemplo, que a prática da masturbação faria crescer pelos nas mãos e caroços no peito. Entretanto, Lima (1990, p. 107) considera que "a masturbação não traz qualquer alteração hormonal e muito menos física", defendendo que a maioria dos medos relacionados à masturbação são infundados cientificamente.

Observaram-se também algumas questões relacionadas às diferenças de gênero. Em uma das atividades realizadas com a $\sigma^{\mathrm{a}}$ série refletiu-se sobre a diferenciação entre o ficar e o namorar. Durante o debate, um dos alunos do sexo masculino classificou como "vadias" as meninas que ficam e transam. No episódio, uma das meninas da sala reagiu ao evidenciar a generalização feita pelo colega de classe, revidando com o mesmo palavreado. Ao presenciar e problematizar essa cena constata-se o quanto ainda estão presentes os valores tradicionais do que vem a ser mulher e homem. Mas, apesar desses valores ainda estarem presentes, há um questionamento por parte das mulheres (no caso, meninas), quanto à sua posição social.

\section{Olhares outros sobre a sexualidade: Kama Sutra}

$\mathrm{Na} 8^{a}$ série, em uma das atividades envolvendo as perguntas que os jovens elaboraram, surgiu uma discussão em que a sexualidade estava sendo vista de uma maneira generalizada e simplificada pela turma. Então o coordenador da atividade aproveitou a situação para problematizar esse conceito, comentando sobre outras culturas que tratam a sexualidade e o sexo de forma distinta da nossa. O livro Kama Sutra foi citado como exemplo. Foram levadas, então, para algumas turmas imagens tridimensionais do Kama Sutra. Escolheram-se imagens não explícitas, ou seja, imagens tridimensionais que remetiam à possibilidade de exercício da sexualidade, seja este com um outro ou individual. Para ver as imagens era necessária a habilidade para enxergar figuras do "olho mágico".

Essa foi uma atividade que despertou grande interesse e foi importante para as reflexões, na medida em que foi possível levar aos alunos um material que continha conteúdo erótico por meio de um viés artístico. Diante do contexto em que vivemos, em que a sexualidade aparece de modo tão apelativo, principalmente como um produto de consumo, faz-se transformador, ao nosso entendimento, mostrar outras formas possíveis de se entrar em contato com diferentes imagens e de expressar sentimentos em relação à sexualidade. O material visual possibilitou problematizar a diferença entre pornográfico e erótico, e lançar a reflexão sobre a sexualidade para outras arenas.

\section{Consideraçóes finais}

O diálogo estabelecido entre a literatura que trata do trabalho com sexualidade nas escolas, bem como a vivência da intervenção aqui apresentada, ainda que brevemente, permitem fazer algumas ponderações referentes à prática dessa temática, conforme preconizado nos PCN, às limitações da psicologia e do próprio estágio.

O estágio contribuiu significativamente para a formação do grupo de estágio enquanto profissionais da psicologia graças à possibilidade de um trabalho interdisciplinar que considerou os saberes da psicologia, da educação e da arte para a compreensão do contexto escolar e, nesse caso mais precisamente, da temática da sexualidade.

Importante se faz abordar a sexualidade para problematizar a questão moral que a regula, e encarar o tema como constituinte da subjetividade humana. Segundo Miguel (2005, p. 31), a "sexualidade possui uma história que deve ser compreendida como construto social e cultural, respeitando sua diversidade e especificidade histórica". Seja qual for o profissional 
que tomar as rédeas dessa tarefa, o importante é fazê-lo de forma aberta e não impositiva e sempre reconhecendo, conforme preconiza os PCN (1997, p. 103), "os valores que regem seus próprios comportamentos e orientam sua visão de mundo, assim como reconhecer a legitimidade de valores e comportamentos diversos dos seus", e dessa forma é possível estabelecer uma relação de confiança com os alunos.

Percebeu-se, entretanto, na permanência na instituição, que algumas prerrogativas dos PCN para a abordagem da temática sexualidade não ocorriam na prática, sobretudo pela precária capacitação dos professores em relação ao tema. Além disso, como transversal, a temática é ao mesmo tempo de todos e de ninguém, já que não se constitui como disciplina curricular, acarretando que a escola a aborde frequentemente de maneira precária.

Nessa escola especificamente a tarefa era relegada à disciplina de ciências e aos conteúdos previstos para as $7^{\mathrm{a}}$ séries sobre o corpo humano e a diferença entre os órgãos sexuais e reprodutivos masculinos e femininos. O professor responsável pela disciplina tinha formação em Física e era contratado temporariamente (ACT). Durante as aulas o professor apresentava imagens do corpo, informações sobre métodos contraceptivos e DSTs. As aulas reduziam, portanto, sexualidade à atividade puramente sexual, vinculava sexo à gravidez, à doença, ao desprazer; impossibilitava qualquer relação entre sexualidade e prazer e sexualidade e afetividade. A atividade sexual, por sua vez, era citada por meio de uma perspectiva moral, em que ficavam explícitos os valores e preconceitos do próprio professor em relação ao tema. Nas intervenções, abordou-se a sexualidade sobre outro prisma, sendo as questões relativas à afetividade destacadas em todos os encontros.

Planejava-se intervir também com a equipe pedagógica, na sua escuta e capacitação; e com as famílias, pois considerava-se fundamental trabalhar com todos os agentes que são parte e participam da vida escolar. Mas como atividade de estágio curricular obrigatório, alguns limites se impuseram, como, por exemplo, o término do período letivo, a carga horária e a impossibilidade de estar na escola todos os dias.

Para finalizar, cabe ressaltar que, assim como muitos professores, o grupo de estágio também encontrou dificuldades em trabalhar com o tema da sexualidade, visto que durante a formação em psicologia o tema não era contemplado a partir de diferentes concepções teóricas e objetivas, ficando restrito a algumas abordagens que priorizam a intervenção na perspectiva clínica. É possível dizer, então, que a sexualidade, ou educação sexual, é também transversal no currículo de psicologia do grupo e provavelmente em vários outros currículos de graduação em psicologia, questão a ser problematizada.

\section{Referências}

Altmann, H. A. (2001). Orientação sexual nos parâmetros curriculares nacionais. Revista Estudos Feministas, 9(2). doi: 10.1590/S0104-026X2001000200014. Recuperado em: 4 dez. 2009, em http://www.scielo. $\mathrm{br} /$ scielo.php?script $=$ sci_arttext\&pid $=$ S0104-026X2 $001000200014 \& \operatorname{lng}=$ en\&nrm $=$ iso

Altmann, H. A. (2007). Sexualidade adolescente como foco de investimento político-social. Educação em Revista, (46). doi: 10.1590/S010246982007000200012. Recuperado em: 4 dez. 2009, em http://www.scielo.br/scielo.php?script $=$ sci_ arttext\&pid $=$ S0102-46982007000200012\&lng $=$ en\& $\mathrm{nrm}=$ iso

Brasil. (1997). Parâmetros Curriculares Nacionais PCN. Orientação sexual. Brasília: MEC/SEF.

Brasil. Lei n. 11.274, de 6 de fevereiro de 2006. Altera a redação dos arts. 29, 30, 32 e 87 da Lei n. 9.394, de 20 de dezembro de 1996, que estabelece as diretrizes e bases da educação nacional, dispondo sobre a duração de 9 (nove) anos para o ensino fundamental, com matrícula obrigatória a partir dos 6 (seis) anos de idade. Diário Oficial [da] República Federativa do Brasil, Poder Legislativo, Brasilia, DF, 6 fev. 2006. Disponível em: <http://www.planalto.gov.br/ccivil_03/_Ato20042006/2006/Lei/L11274.htm>. Acesso em:23 jul. 2010.

Bretas, J. R. da S., \& Silva, C. V. da. (2005). Orientação sexual para adolescentes: Relato de experiência. Acta Paulista de Enfermagem, 18(3). doi: 10.1590/ S0103-21002005000300015. Recuperado em: 4 dez. 2009, em http://www.scielo.br/scielo.php?script=sci_ arttext\&pid=S0103-21002005000300015\&lng $=$ pt\& $\mathrm{nrm}=$ iso

Dinis, N., \& Asinelli-Luz, A. (2007). Educação sexual na perspectiva histórico-cultural. Educar em Revista, (30). doi: 10.1590/S0104-40602007000200006. Recuperado em: 4 dez. 2009, em http://www. scielo.br/scielo.php?script $=$ sci_arttext\&pid $=$ S0104$-40602007000200006 \& \operatorname{lng}=$ en $\& \mathrm{nrm}=$ is o 
Foucault, M. História da sexualidade. (9. ed.) Rio de Janeiro: Graal, 1988.

Lima, H. Educação sexual para adolescentes: Desenvolvendo o corpo e os mitos. São Paulo: Iglu, 1990.

Maheirie, K., Urnau, L. C., Vavassori, M. B., Orlandi, R., \& Baierle, R.E. (2005). Oficina sobre sexualidade com adolescentes: Um relato de experiência. Psicologia em estudo, 10(3), 537-542. Recuperado em: 4 nov. 2008, em http://www.scielo.br/pdf/pe/v10n3/ v10n3a21.pdf

Meirelles, J. A. B. (1997). Os ETs e a gorila. Um olhar sobre a sexualidade a família e a escola. In J. G. Aquino. Sexualidade na escola, alternativas teóricas e práticas (pp. 71-86). São Paulo: Summus.

Miguel, R. B. P. (2005). De “moça prendada” à “menina super-poderosa": Um estudo sobre as concepções de adolescência, sexualidade e gênero na imprensa feminina. Florianópolis: UFSC.

Organização Mundial da Saúde - OMS. (1960). Documentos básicos. (10a ed.) Genebra: OMS.

Zanella, A. (1998). Psicología social e escola. In:M. N. Strey. Psicologia social contemporânea. Petrópolis: Vozes.

Zanella, A. (2003). Vygotki. Psicologia histórico-cultural e prática pedagógica: breves considerações. In: F. C. B. Costa, L. Bianchetti, O. \& Evangelista. Escola viva: A construção do projeto político pedagógico do Colégio de Aplicação da UFSC (pp. 151-163). Florianópolis: NUP/CED/UFSC.

Zanella, A. (2001). A relação desenvolvimento e aprendizagem em vygotsky e o conceito de "zona de desenvolvimento proximal”. In A. Zanella. Vygotski: Contexto, contribuições à psicologia e o conceito de zona de desenvolvimento proximal. Itajaí: Ed. Univali.

Recebido: 09/03/2010

Received: 03/09/2010

Aprovado: 19/05/2010

Approved: 05/19/2010 